\title{
PHYSICAL ACTIVITY CAN BOOST EMOTIONAL QUALITY OF LIFE IN BREAST CANGER SURVIVORSA SUB-SET ANALYSES OF KROG 14-09 NATIONWIDE QUESTIONNAIRE STUDY
}

\author{
W.S. Yoon, S.J. Ahn, J.H. Kim, M. Chun, C.H. Rim, D.S. Yang, J.H. Lee, K. Kim, M. Kong, S. Kim, J. Kim, K.R. \\ Park, Y.J. Shin, S.Y. Ma, B.K. Jeong, S.S. Kim, Y.B. Kim, D.S. Lee \\ The Division of Breast Cancer, Korean Radiation Oncology Group
}

Background: To investigate the relation between physical activity (PA) and quality of life (QoL) through nationwide multiinstitutional questionnaires.

Methods: Data from 1156 questionnaires obtained from breast cancer survivors after adjuvant radiotherapy were analyzed. After screening uncertain information and heavy activity for PA ( $>900$, minutes/week), 682 questionnaires were available and divided by three groups of inactivity $(<150)$, regular activity $(150-450)$ and moderate activity $(<450-900)$. Global physical activity question, 5-dimensional questionnaire by EuroQol (EQ-5D), EORTC QLQ-BR23 and were used including clinical and socio-demographic information. A linear-to-linear correlation test and Spearman's test for each item of EQ-5D and summation of EQ-5D, respectively and multiple comparison by Tukey test after Kruskal-Wallis analysis for QLQ-BR23 were conducted.

Results: 144 (21.1\%), 309 (45.3\%) and 229 (33.6\%) survivors had inactivity, regular PA and moderate PA, respectively. There was no difference for age groups $(P=0.246)$. The age distribution For EQ-5D, mobility $(P=0.021)$, usual activity $(P=0.049)$ and anxiety $(P=0.022)$ were aggravated in inactive $P A$. The survivors showing scale 5 for summation of EQ-5D (the best score on all 5 items) were $24.8 \%, 32.1 \%$ and $39.0 \%$ for inactive, regular and moderate $\mathrm{PA}$, respectively and the extent of PA was inversely correlated with summation of EQ-5D ( $P=0.004)$. For $Q L Q-B R 23$, systematic therapy symptom $(P=0.010)$, and body image $(P=0.048)$ and future perspective $(P=0.004)$ for functional area were improved by regular and moderate PA. However, the differences between regular and moderate PA were insignificant in all areas.

\begin{tabular}{|c|c|c|c|c|c|}
\hline $\begin{array}{l}\text { Physical } \\
\text { activity }\end{array}$ & $\begin{array}{r}\text { Mobility } \\
1: 2: 3\end{array}$ & $\begin{array}{r}\text { Self- } \\
\text { Manage } \\
\text { ment } \\
1: 2: 3\end{array}$ & $\begin{array}{r}\text { Usual } \\
\text { Activity } \\
1: 2: 3\end{array}$ & $\begin{array}{r}\text { Pain } \\
\text { 1: 2:3 }\end{array}$ & $\begin{array}{r}\text { Anxiety } \\
1: 2: 3\end{array}$ \\
\hline P value & 0.021 & 0.900 & 0.049 & 0.105 & 0.022 \\
\hline \multirow[t]{3}{*}{ Inactive } & 85.1: & 97.2: & 82.3: & 41.1: & 52.5: \\
\hline & 14.2: & 2.8: & 17.7: & 56.7: & 46.8: \\
\hline & 0.7 & 0.0 & 0.0 & 2.1 & 0.7 \\
\hline \multirow[t]{3}{*}{ Regular } & 86.6: & 97.1: & 85.9: & 50.0: & 56.4: \\
\hline & 13.4: & 2.9: & 13.7: & 50.0: & 42.0: \\
\hline & 0.0 & 0.0 & 0.3 & 0.0 & 1.6 \\
\hline \multirow[t]{3}{*}{ Moderate } & 92.1: & 97.4: & 89.5: & 50.0: & 63.6: \\
\hline & 7.9: & 2.2: & 10.5: & 49.1: & 36.4: \\
\hline & 0.0 & 0.4 & 0.0 & 0.9 & 0.0 \\
\hline
\end{tabular}
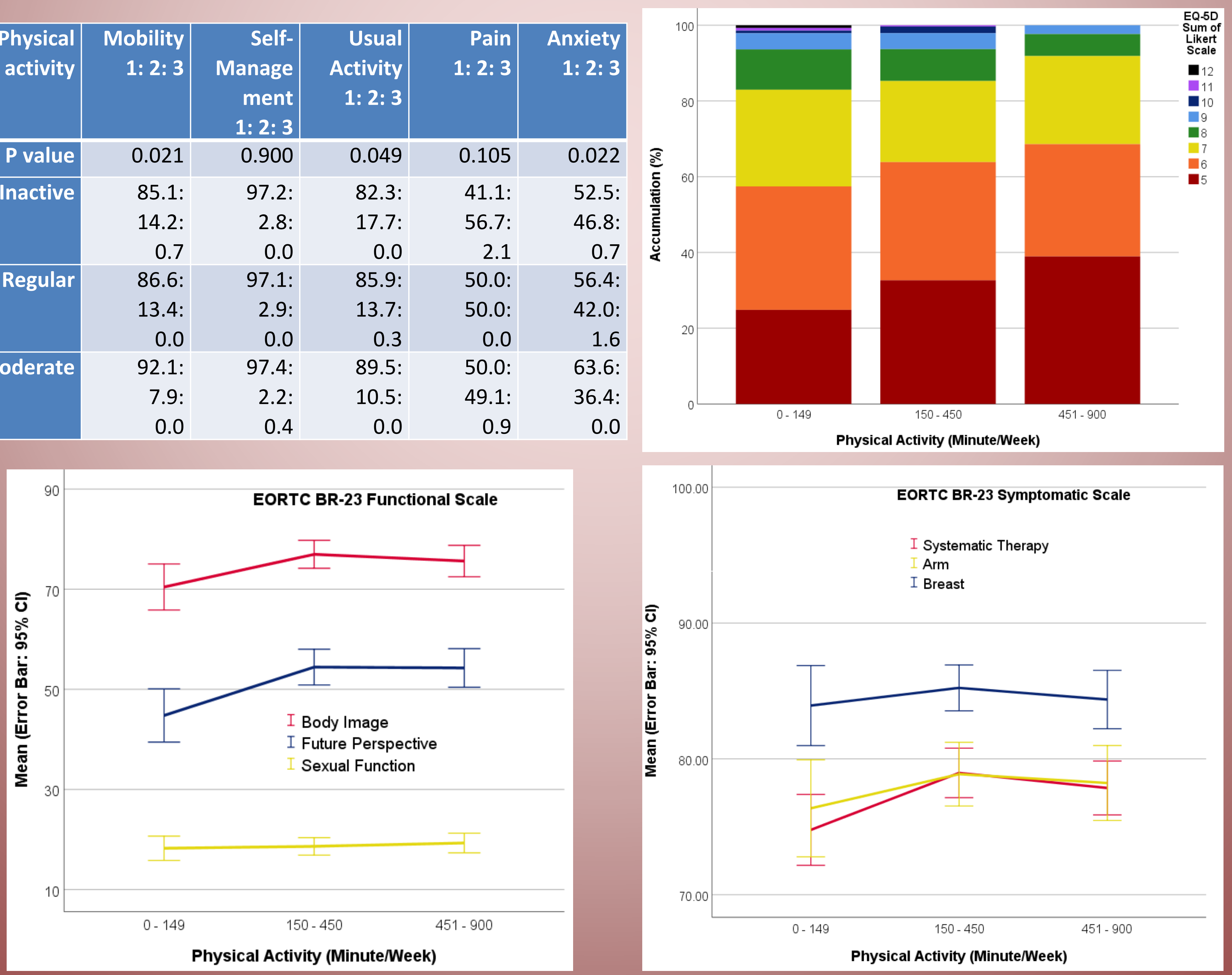

Conclusion: Emotional and physical quality of life could be improved by physical activity. However, involvement in physical activity over regular extent could have a minimal impact on quality of life . 